\title{
U so de diferentes doses de manipueira na cultura da alface em substituição à adubação mineral
}

\author{
Anamaria de S. Duarte', Ênio F. de F. e Silva ${ }^{1}$, Mario M. Rolim ${ }^{1}$, \\ Rafael F. de A.e L. Ferreira², Samuel M. M. Malheiros ${ }^{2} \&$ Francimar da S. Albuquerque $^{3}$
}

RESU M O

Objetivou-se, neste trabalho, verificar o efeito ocasionado pelo uso de diferentes doses de manipueira nas características agronômicas da alface em substituição à adubação mineral. 0 referido estudo foi desenvolvido em uma área pertencente ao Departamento de Tecnologia Rural da U niversidade Federal Rural de Pernambuco, Recife, PE, no período de maio a agosto de 2010. 0 experimento foi conduzido em ambiente protegido em delineamento inteiramente casualizado, com seis tratamentos compostos das seguintes doses: $0,5,15,25,45,65 \mathrm{~m}^{3} \mathrm{ha}^{-1}$ e cinco repetições. U tilizou-se a cultivar de alface Regina 2000, dispondo-se uma planta por vaso de 4 L. Foram avaliadas, em função das doses aplicadas, as seguintes características agronômicas da alface: área foliar, altura de planta, número de folhas, matéria fresca e matéria seca da alface. Ao final do experimento constatou-se que a dose de $45 \mathrm{~m}^{3} \mathrm{ha}^{-1}$ foi a que propiciou maior ganho de altura de planta, área foliar e, consequentemente, também maior produção de matéria fresca e seca. Assim sendo, o uso da manipueira serviu como fonte de adubação para a cultura da alface, dependendo da dose aplicada.

Palavras-chave: M anihot esculenta crant, Lactuca sativa L., biofertilizante

\section{U se of different doses of cassava wastewater in lettuce crop in substitution of mineral fertilizer}

\begin{abstract}
A B ST RACT
The main goal of this work was to evaluate the effect on agronomic characteristics of the lettuce when using different doses of cassava wastewater instead of mineral fertilizer. This study was conducted at the Departamento de Tecnologia Rural da Universidade Rural de Pernambuco, Recife, PE, from May to August 2010. The experiment was carried out under greenhouse conditions in a completely randomized blocks, with six treatments and five repetitions. Following doses were used: 0, 5, 15, 25, 45 and $65 \mathrm{~m}^{3} \mathrm{ha}^{-1}$. The lettuce cultivar Regina 2000 was used (one plant per pot) and leaf area, plant height, number of leaves, fresh leaf mass and dry leaf mass were evaluated for each dose of cassava wastewater. At the end of the experiment, the dose of $45 \mathrm{~m}^{3} \mathrm{ha}^{-1}$ provided the best results by increasing plant height, leaf area, fresh and dry material. Thus, the cassava wastewater can be successfully used as a source of fertilizer for a lettuce crop if the adequate dose is used.
\end{abstract}

Key words: Manihot esculenta crantz, Lactuca sativa L., biofertilizer

\footnotetext{
${ }^{1}$ U FRPE. Rua Dom Manoel de Medeiros, s/n, CEP 52171-900, Recife, PE. Fone: (81) 3320-6276/3320-6279. E-mail: asousaduarte@gmail.com, enio.silva@dtr.ufrpe.br, rolim@dtr.ufrpe.br

2 Mestrando do Programa Eng. Agrícola e Ambiental/UFRPE. E-mail: raferural@hotmail.com, samuelmarcus@click21.com.br

D outorando do Programa Eng. Agrícola e Ambiental/U FRPE. E-mail: franciufrpe@gmail.com
} 


\section{INTRODUÇÃO}

A utilização de efluentes e resíduos de origem agroindustrial como fonte complementar de água e nutrientes para a fertirrigação ou como biofertilizantes não é recente (Silva et al. 2003). Reporta-se que, na década de 50, com o aparecimento das amidonarias, começaram a ser utilizados os subprodutos do beneficiamento da mandioca nas atividades agropecuárias devido ao aporte de nutrientes relacionados a esses insumos e pela falta de acesso às informações sobre o tratamento dos efluentes e resíduos gerados pelo beneficiamento da mandioca.

A manipueira é um dos resíduos gerados no processamento da mandioca (Manihot esculenta Crantz) para obtenção da farinha ou fécula. Tal resíduo é um líquido leitoso amareloclaro, que contém açúcares, amidos, proteínas, linamarina, sais e outras substâncias. A linamarina é um glicosídeo cianogênico tóxico, do qual provém o ácido cianídrico (HCN), que é bastante volátil e pode trazer riscos ambientais caso a manipueira seja descartada "in natura" no meio ambiente (Cereda, 2001).

De acordo com Wosiacki \& Cereda (2002), a disposição indiscriminada desse efluente, conhecido pelo poder poluidor e elevada toxidez no meio ambiente, traz graves danos ambientais: seu descarte em corpos aquáticos reduz a disponibilidade de oxigênio dissolvido no meio, causando a morte dos organismos aeróbios e seu lançamento no solo prejudica o equilíbrio entre nutrientes, aumenta a salinidade e diminui o $\mathrm{pH}$.

Alguns pesquisadores consideram que a manipueira pode ser reaproveitada de diversas formas: como pesticida (Magalhães et al., 2000), nematicida (Nasu et al. 2010), adsorção de metais pesados (Horsfall Júnior \& Abia, 2003) e como fertilizante (Fioretto, 1997).

Estudando o possível uso da manipueira como insumo agrícola, Mélo et al. (2005) concluíram que a concentração de cálcio, potássio, sódio e magnésio trocáveis aumentaram linearmente em três diferentes solos tratados com manipueira, e Pinho (2007) concluiu que a aplicação de doses crescentes de manipueira aos solos elevou significativamente a produção de matéria seca da parte aérea da mandioca; entretanto, Ribas et al. (2010) relatam que, além do nitrogênio, fósforo e potássio, a manipueira contém altas concentrações de sódio, ferro, zinco, cobre, ácido cianídrico, DBO e DQO, o que dificulta seu tratamento e, por conseguinte, reduz seu uso como fertilizante agrícola. Por outro lado, se o uso da manipueira não for realizado de forma indiscriminada, respeitando-se a composição química do solo e as doses toleradas pelas culturas, a aplicação de tal resíduo como insumo agrícola resolveria, simultaneamente, o problema da poluição ambiental e ainda traria benefícios agrícolas.

Desta forma e devido ao grande volume gerado de manipueira que, na maioria das vezes, é descartado no meio ambiente de forma indiscriminada, tal como à facilidade e ao baixo custo de obtenção do resíduo junto às casas de farinha, o objetivo deste estudo foi avaliar o efeito ocasionado pelo uso de diferentes doses de manipueira nas características agronômicas da alface, em substituição à adubação mineral.

\section{Material E MÉTODOS}

O experimento foi conduzido em uma casa de vegetação pertencente ao Departamento de Tecnologia Rural da Universidade Federal Rural de Pernambuco, Recife, PE, cujas coordenadas geográficas são: $08^{\circ} 01^{\prime} 01^{\prime \prime}$ de latitude Sul e $34^{\circ}$ 56' 47" de longitude Oeste.

O clima, de acordo com a classificação de Koppen, é Megatérmico Tropical (tropical úmido), com temperatura média do mês mais frio superior a $18{ }^{\circ} \mathrm{C}$ e com precipitação média de $1750 \mathrm{~mm}$ ao ano (Brasil, 1992).

A casa de vegetação media 7,0 $\mathrm{m}$ de largura, 24,0 $\mathrm{m}$ de comprimento, 3,0 $\mathrm{m}$ de pé direito e 4,5 $\mathrm{m}$ de altura com cobertura em arco. As laterais tinham revestimento de tela tipo sombrite $50 \%$ e possuíam um rodapé de $20 \mathrm{~cm}$ em alvenaria. A cobertura do ambiente era em filme agrícola de polietileno, com $150 \mu \mathrm{m}$ de espessura e tratamento anti-ultravioleta. $\mathrm{O}$ piso foi revestido com manta geotêxtil na cor cinza (bidim), com o objetivo de melhorar as condições fitossanitárias e minimizar os efeitos da poeira sobre a casa de vegetação.

Utilizou-se, no experimento, um solo classificado como Neossolo Regolítico Distrófico, coletado na profundidade de 0 a $20 \mathrm{~cm}$. Visando à caracterização física e química do solo, cinco amostras simples foram coletadas por meio de trado, seca ao ar, destorroadas e peneiradas em malha de $2 \mathrm{~mm}$ sendo, posteriormente, misturadas, formando uma amostra composta. Não se realizou qualquer tipo de adubação mineral ou calagem no solo.

A caracterização química e física do solo (Tabela 1) foi realizada nos Laboratórios de Fertilidade do Solo e Física do Solo, ambos pertencentes à UFRPE, seguindo-se os métodos descritos pela EMBRAPA (1997).

Tabela 1. Características físicas e químicas do solo utilizado

\begin{tabular}{lc}
\hline \multicolumn{1}{c}{ Parâmetros } & Teor \\
Areia $\left(\mathrm{g} \mathrm{kg}^{-1}\right)$ & 697 \\
Silte $\left(\mathrm{g} \mathrm{kg}^{-1}\right)$ & 147 \\
Argila $\left(\mathrm{g} \mathrm{kg}^{-1}\right)$ & 157 \\
Densidade do solo $\left(\mathrm{kg} \mathrm{dm}^{-3}\right)$ & 1,32 \\
pH em água & 5,84 \\
Potássio $\left(\mathrm{cmol}_{\mathrm{c}} \mathrm{kg}^{-1}\right)$ & 0,18 \\
Sódio $\left(\mathrm{cmol}_{\mathrm{c}} \mathrm{kg}^{-1}\right)$ & 0,04 \\
Cálcio $\left(\mathrm{cmol}_{\mathrm{c}} \mathrm{kg}^{-1}\right)$ & 0,75 \\
Magnésio $\left(\mathrm{cmol}_{\mathrm{c}} \mathrm{kg}^{-1}\right)$ & 0,40 \\
Fósforo $\left(\mathrm{mg} \mathrm{kg}^{-1}\right)$ & 0,80 \\
Matéria orgânica $\left(\mathrm{g} \mathrm{kg}^{-1}\right)$ & 3,58 \\
\hline
\end{tabular}

A irrigação foi feita levando-se em consideração a capacidade de campo do solo e, para tanto, testes de pesagem dos vasos foram realizados, os quais foram preenchidos da seguinte forma: $500 \mathrm{~g}$ de brita número 0 , que permitia a drenagem da água; manta bidim, que servia para evitar a perda de solo e $3000 \mathrm{~g}$ de solo, utilizados para o cultivo. Após a montagem, os vasos foram saturados e pesados diariamente, até se obter peso constante, ou seja, quando o solo se encontrava em capacidade de campo.

A partir desses testes, obteve-se o peso médio do conjunto com solo em capacidade de campo e como todos os vasos 
utilizados para o plantio no experimento foram preenchidos da mesma forma, o volume de água necessário para cada planta foi obtido pela diferença do peso médio do conjunto com o solo em capacidade de campo e o peso de cada vaso contendo uma planta, que era medido diariamente.

Neste experimento, realizado de maio a agosto de 2010, foi utilizada como cultura teste a alface cultivar Regina 2000, que se caracteriza por ter folhas lisas, ser precoce, com ciclo de 60 a 65 dias após a semeadura, apresentar alta produtividade e ser resistente ao tip burn e ao pendoamento prematuro, devido às altas temperaturas e ao Lettuce Mosaic Virus (LMV) par o tipo II.

As mudas foram preparadas em bandejas de isopor contendo 120 células, que foram preenchidas com uma mistura de vermiculita e pó de coco. Após o período de vinte e cinco dias, as plantas com 3 pares de folhas definitivas foram transplantadas manualmente em vasos com capacidade igual a $4 \mathrm{~L}$, os quais receberam brita, bidim e o material de solo. A massa de solo colocada em cada vaso foi determinada com base na densidade do solo e no volume do vaso.

O experimento foi conduzido em casa de vegetação, em delineamento experimental inteiramente casualizado, com seis tratamentos e cinco repetições, sendo os tratamentos compostos das seguintes doses de manipueira: 0, 5, 15, 25, 45 $65 \mathrm{~m}^{3} \mathrm{ha}^{-1}$, correspondendo aos volumes de 0 (ausência de manipueira), 150, 450, 750, 1350 e $1950 \mathrm{~mL}$ de efluente, que foram aplicados em cada vaso de 4L. Para os três últimos volumes realizou-se um fracionamento para que não houvesse perda da manipueira devido à saturação do solo. Após a aplicação da manipueira todos os vasos foram envoltos em papel alumínio e ficaram incubados durante 21 dias. Para melhor compreensão, os tratamentos serão denominados T0, T1, T2, T3, T4 e T5 e corresponderão, respectivamente, às seguintes doses de manipueira: $0,5,15,25,45,65 \mathrm{~m}^{3} \mathrm{ha}^{-1}$.

As doses de manipueira foram calculadas levando-se em consideração a concentração de potássio nela existente e no solo, bem como a exigência desse nutriente pela alface. Ressalta-se que não foi necessário realizar calagem e também não se utilizou adubação mineral durante o experimento, com o intuito de avaliar apenas o efeito que o uso da manipueira exerceu sobre a cultura.

A manipueira utilizada proveio de uma casa de farinha localizada no município de Pombos, PE. A determinação da composição física e química da manipueira (Tabela 2) foi realizada no Laboratório de Análises Agrícolas (LAGRI) e no Laboratório de Análise de Resíduos da UFRPE. Os parâmetros físicos e químicos foram determinados de acordo com a metodologia proposta por APHA (1995).

Para acompanhar o desenvolvimento das plantas foram monitorados os seguintes parâmetros: altura de plantas e número de folhas, com frequência semanal; massa verde e massa seca da parte aérea das plantas, por ocasião do final do experimento, conforme metodologia proposta por Benincasa (2003) e área foliar através de um medidor de área foliar.

\section{RESULTADOS E DISCUSSÃO}

Em relação à área foliar (Figura 1), a manipueira promoveu efeito quadrático e as plantas que foram cultivadas no solo
Tabela 2. Características físicas e químicas da mani pueira

\begin{tabular}{lc}
\hline \multicolumn{1}{c}{ Parâmetros } & Teor \\
Sólidos sedimentáveis $\left(\mathrm{mL} \mathrm{L}^{-1}\right)$ & 17,20 \\
$\mathrm{pH}$ & 4,08 \\
Nitrogênio $\left(\mathrm{mg} \mathrm{L}^{-1}\right)$ & 980 \\
Fósforo $\left(\mathrm{m} \mathrm{L}^{-1}\right)$ & 740 \\
Potássio $\left(\mathrm{mg} \mathrm{L}^{-1}\right)$ & 1970 \\
Sódio $\left(\mathrm{mg} \mathrm{L}^{-1}\right)$ & 460 \\
Cálcio $\left(\mathrm{m} \mathrm{L}^{-1}\right)$ & 240 \\
Magnésio $\left(\mathrm{mg} \mathrm{L}^{-1}\right)$ & 360 \\
Zinco $\left(\mathrm{mg} \mathrm{L}^{-1}\right)$ & 2,60 \\
Cobre $\left(\mathrm{mg} \mathrm{L}^{-1}\right)$ & 2,80 \\
Manganês $\left(\mathrm{mg} \mathrm{L}^{-1}\right)$ & 20,00 \\
Ferro $\left(\mathrm{mg} \mathrm{L}^{-1}\right)$ & 10,00 \\
\hline
\end{tabular}

que recebeu $1350 \mathrm{~mL}$ de manipueira (correspondente à dose de $45 \mathrm{~m}^{3} \mathrm{ha}^{-1}$ ) apresentaram os maiores valores deste parâmetro (média de 29,62 $\mathrm{cm}^{2}$ ). Constatou-se, ainda, ganho de área foliar em relação à testemunha (T0) e aos tratamentos T1, T2 e T3, cujas doses aplicadas foram de 5, 15 e $25 \mathrm{~m}^{3} \mathrm{ha}^{-1}$.

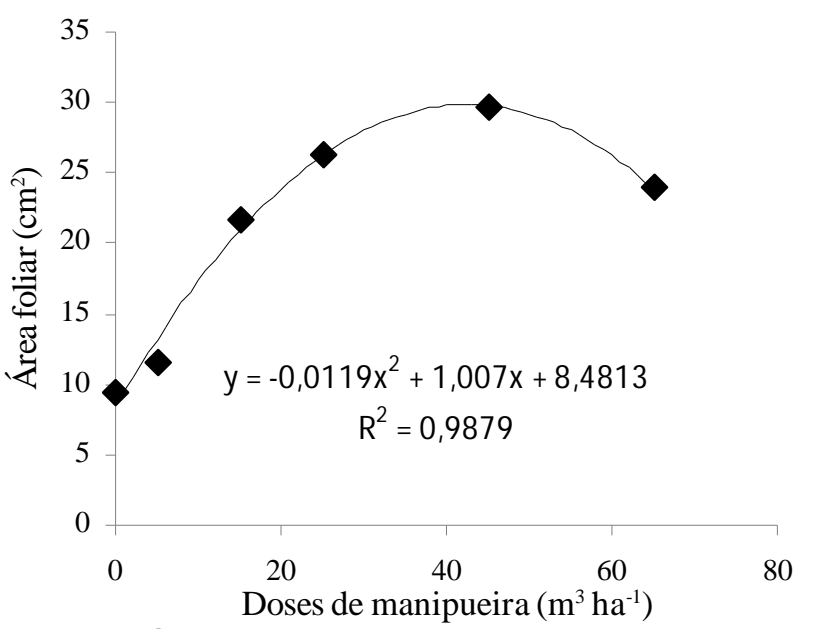

Figura 1. Área foliar da alface em função das doses de manipueira

Santos et al. (2010) relataram, cultivando alfaces adubadas com manipueira, que a área foliar aumentou, de forma quadrática, em função de doses crescentes de tal resíduo. $\mathrm{Na}$ ocasião, a área foliar média mostrou, para o tratamento, que a melhor resposta foi de $16,67 \mathrm{~cm}^{2}$, bem menor, portanto, que a área foliar das plantas cultivadas sob influência das doses iguais a $15,25,45,65 \mathrm{~m}^{3} \mathrm{ha}^{-1}$.

Apesar dos resultados se mostrarem positivos à aplicação da manipueira, nota-se, para doses maiores que $45 \mathrm{~m}^{3} \mathrm{ha}^{-1}$ (Figura 1A), que a área foliar começou a decair. Este fato pode ter ocorrido devido a algum efeito deletério de nutrientes, sobretudo do potássio que, em excesso, compromete a absorção de outros elementos pela planta, como o cálcio, o magnésio, o zinco e o manganês (Malavolta, 1997).

Prado et al. (2004) verificaram decréscimo de área foliar quando estudaram a aplicação de doses crescentes de potássio na cultura do maracujá, sendo que as doses adequadas deveriam ser menores que $300 \mathrm{mg} \mathrm{dm}^{-3}$.

De acordo com a curva exposta na Figura 2A, verifica-se que as plantas que receberam as maiores doses de manipueira 
apresentaram também maior altura em relação à testemunha (T0), sendo que as plantas cultivadas sob o efeito da dose de $45 \mathrm{~m}^{3} \mathrm{ha}^{-1}$ foram significativamente mais altas do que as outras cultivadas nos demais tratamentos.

Na Figura 2B observa-se que o número de folhas aumentou em função do aumento das doses do resíduo, até o ponto máximo de resposta obtida para a dose de $25 \mathrm{~m}^{3} \mathrm{ha}^{-1}$, com valor médio estimado de 38 folhas. Ficou comprovado, pela equação de regressão, que doses acima deste valor acarretaram um decréscimo quadrático no número de folhas.
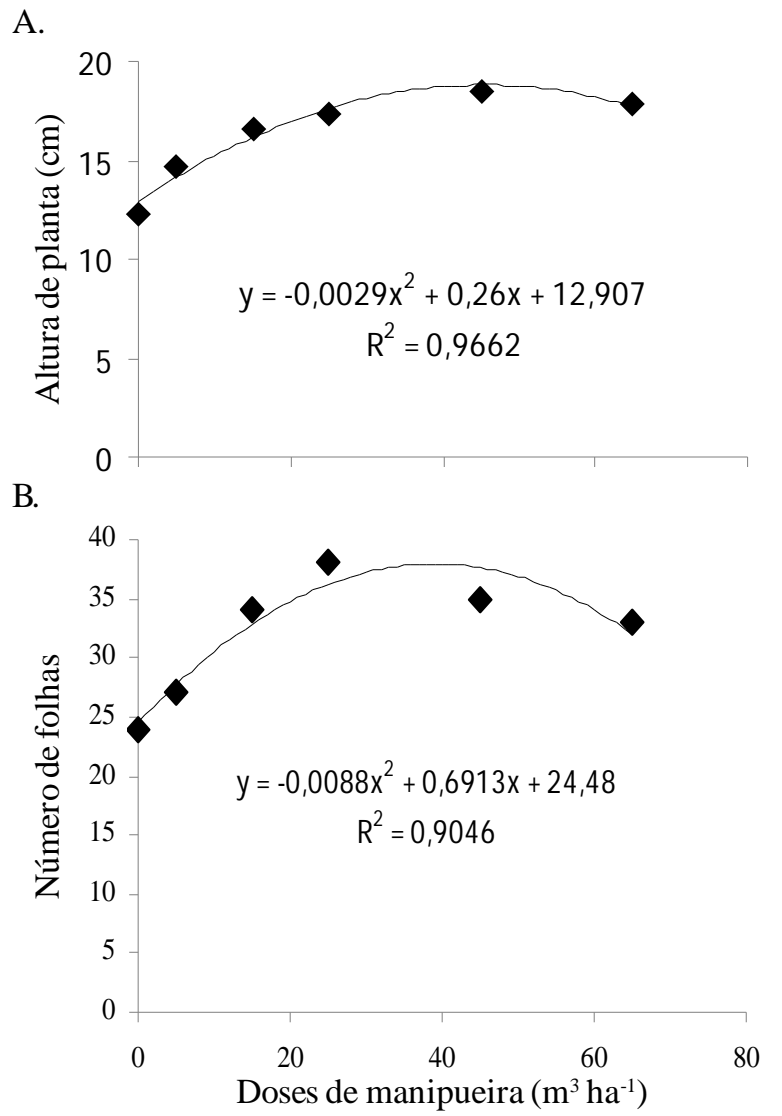

Figura 2. Altura de planta $(A)$ e número de folhas $(B)$ da alface em função das doses de manipueira

Trabalhando com a incorporação de manipueira tratada no solo, Ribas et al. (2010) afirmam que as características agronômicas do milho (altura de planta, diâmetro do caule e massa fresca) avaliadas no estudo não foram afetadas negativamente pelo uso do efluente.

Pelas Figuras 3A e 3B verifica-se que a tendência observada para as varáveis massa fresca e massa seca da parte aérea foi semelhante à tendência mostrada pelos parâmetros área foliar e altura de plantas, ou seja, à medida em que a dose aplicada do resíduo aumentou, os valores estimados de massa fresca e massa seca da parte aérea foram significativamente maiores, decaindo após atingir o ponto máximo correspondente a 45 $\mathrm{m}^{3} \mathrm{ha}^{-1}$.

A matéria fresca a matéria seca da parte aérea das plantas apresentaram valores máximos de 90,3 e 4,86 $\mathrm{g}_{\text {plantas }}{ }^{-1}$, respectivamente, evidenciando o efeito quadrático do aumento das doses de manipueira.

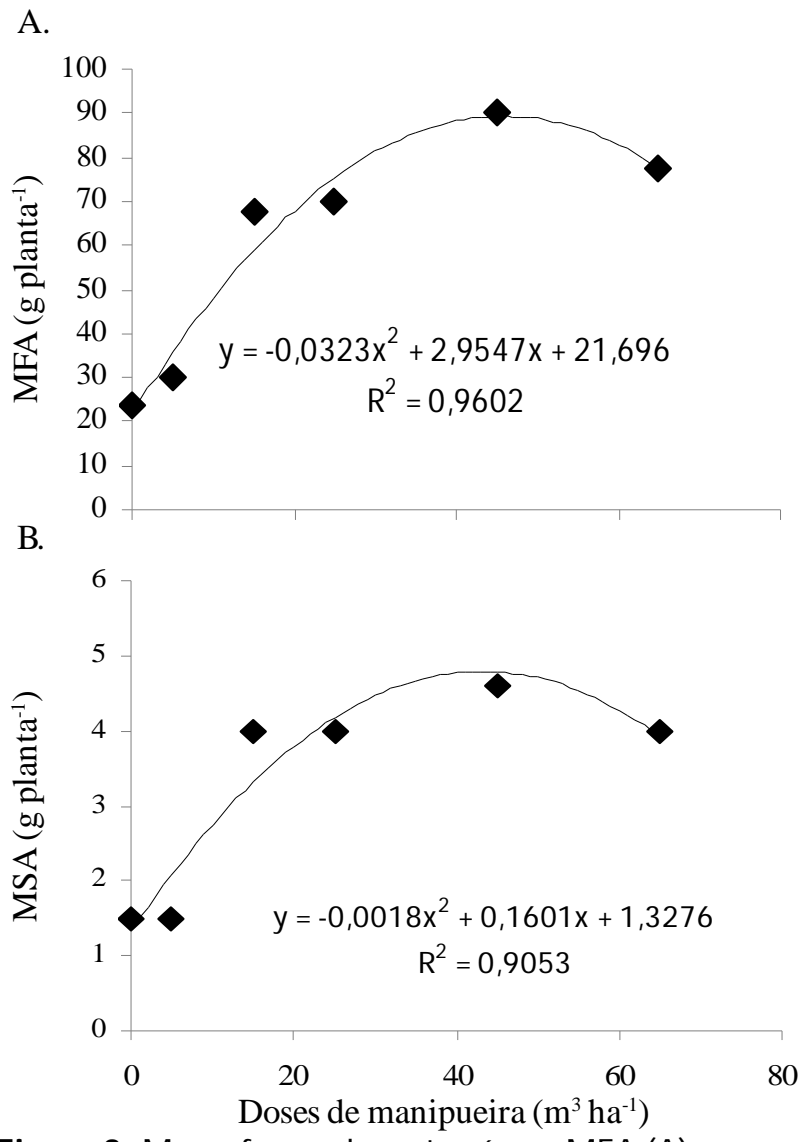

Figura 3. Massa fresca da parte aérea - MFA (A) e massa seca da parte aérea - MSA (B) da alface em função das doses de manipueira

Em consonância com os dados obtidos neste estudo, Cardoso et al. (2009) afirmam que o milho cultivado em área biofertilizada com manipueira apresentou maior produtividade e massa fresca da parte aérea que o milho cultivado em solo adubado com fertilizante mineral, sendo este aumento creditado ao poder fertilizante da manipueira, principalmente aos elementos potássio e nitrogênio.

Resposta semelhante obtiveram Cabral et al. (2010), quando utilizaram efluente de manipueira para a adubação do solo e cultivaram aveia preta. Além disso, os autores constataram que apenas o teor de potássio aumentou nas camadas do solo enquanto os outros elementos apresentaram redução.

Por outro lado, Vieites (1998) verificou que o uso de tal resíduo como adubo contribuiu para aumentar o rendimento, o diâmetro e o comprimento dos frutos comercializáveis do tomateiro, porém foi necessária a complementação de $50 \%$ de adubação mineral, e Schwengber et al. (2010) afirmaram que o desenvolvimento dos nódulos e o crescimento do feijão caupi foram significativamente menores nas plantas que receberam manipueira do que nas plantas que receberam adubação mineral.

Em geral, a adubação orgânica dificilmente prescinde da adubação química para que produções satisfatórias sejam alcançadas (Resende et al., 2009).

Avaliando a resposta decorrente da aplicação de doses crescentes de adubação nitrogenada na alface, cultivar Verônica, Araújo et al. (2011) obtiveram uma relação linear decrescente, 
sendo que o tratamento sem adição de $\mathrm{N}$ apresentou maior produção $\left(187,67 \mathrm{~g}_{\text {plantas }}{ }^{-1}\right)$. Em outro estudo, com o objetivo de determinar a produção de diversas cultivares de alface em função de doses crescentes de nitrogênio, Mantovani et al. (2005) obtiveram uma produção média de massa fresca da parte aérea igual a $533 \mathrm{~g}$ planta $^{-1}$ para a cultivar Verônica, maior, portanto, que a produção encontrada para as plantas cultivadas neste estudo.

Por outro lado, quando utilizaram fertilizantes orgânico e mineral para a adubação da alface, cultivar Kaesar, Teixeira et al. (2004) obtiveram uma produção média de $1030 \mathrm{~g} \mathrm{plantas}^{-1}$, mostrando que a associação da adubação orgânica com a adubação mineral pode ser rentável, além de possibilitar economia de fertilizantes.

De acordo com Sandri et al. (2007), a área foliar reflete a capacidade fotossintética das plantas e, juntamente com os dados de altura de planta, número de folhas, massa fresca e massa seca, mostra como a planta se desenvolveu. Concordando com esses autores e mediante os dados expostos neste trabalho, tem-se que as plantas submetidas às doses crescentes de manipueira se desenvolveram melhor, uma vez que apresentaram maior índice de área foliar e demais parâmetros fenológicos analisados.

Assim, com os resultados aqui obtidos, pode-se afirmar que a manipueira pode ser utilizada como fonte de nutrientes. Entretanto, se tal resíduo não for utilizado adequadamente poderá causar danos, tanto ao solo quanto às culturas, já que o excesso de nutrientes no solo, sobretudo o potássio e o sódio, poderá provocar a dispersão de argilas e, consequentemente, o desequilíbrio nutricional das plantas, conforme comprovado por Mélo et al. (2005).

\section{ConclusõEs}

1. O uso da manipueira serviu como fonte de adubação para a cultura da alface, sendo necessária a utilização de doses adequadas para evitar o efeito deletério de alguns nutrientes, sobretudo do potássio, íon encontrado em maior concentração neste resíduo.

2. Em geral, a dose de $45 \mathrm{~m}^{3} \mathrm{ha}^{-1}$ foi a que propiciou maior ganho de altura de planta, área foliar e, em consequência, maior produção de matéria fresca e seca da parte aérea. A partir desta dose, constatou-se declínio nos valores das características agronômicas da cultura cultivada.

\section{AgradeCIMENTOS}

Os autores agradecem à Sociedade Nordestina de Ecologia (SNE) e ao Serviço de Tecnologia Alternativa (SERTA) pela concessão da manipueira utilizada no experimento e à Coordenação de Aperfeiçoamento de Pessoal de Nível Superior (CAPES) pelo auxílio financeiro.

\section{LITERATURA CITADA}

Araújo, W. F.; de Sousa, K. T. S.; Viana, T. V. A.; de Azevedo, B. M.; Barros, M. M.; Marcolino, E. Resposta da alface a adubação nitrogenada. Revista Agro@ mbiente On-line, v. 5, p. 12-17, 2011.

APHA - American Public Health Association, AWWA American Water Works Association, WPCF - Washington Press Club Foundation. Standard methods for the examination of water and wastewater. Washington: American Public Health Association, 17.ed. 1995. 2198p.

Benincasa, M. M. P. Análise de crescimento de plantas: Noções básicas. 2.ed. Jaboticabal: FUNEP, 2003. 41p.

Brasil. Ministério da Agricultura e Reforma Agrária. Secretaria Nacional da Irrigação. Departamento de Meteorologia. Normas Climatológicas 1961-1990. Brasília: EMBRAPA, 1992. $84 \mathrm{p}$.

Cereda, M. P. Manejo, uso e tratamento de subprodutos da industrialização da mandioca. 1.ed. São Paulo: Fundação Cargill, 2001. 320p.

Cabral, J. R.; Freitas, P. S. L.; Bertonha, A.; Muniz, A. S. Effects of wastewater from a cassava industry on soil chemistry and crop Yield of lopsided oats (Avena strigosa Schreb) Brazilian Archives of Biology and Technology, v.53, p.1926. 2010.

Cardoso, E.; Cardoso, D.; Cristiano, M.; Silva, L.; Back, A.J.; Bernadim, A. M.; Paula, M. M. S. Use of manihot esculenta, crantz processing residue as biofertilizer in corn crops. Research Journal of Agronomy, v.3, p.1-8, 2009.

EMPRESA - Empresa Brasileira de Pesquisa Agropecuária. Manual de métodos de análises de solo. 2.ed. Rio de Janeiro: Centro Nacional de Pesquisa de Solos, 1997. 212p.

Fioretto, R. A. Manipueira na fertirrigação: efeito sobre a germinação e a produção de algodão (Gossypium hirsutm, L.) e milho (Zea mays, L.). Semina, v.8, p.17-20, 1987.

Horsfall Júnior, M.; Abia, A. A. Sorption of cadmium (II) and zinc (II) ions from aqueous solutions by cassava waste biomass (Manihot sculenta, Crantz). Water Resource, v.37, p.4913-4923, 2003.

Magalhães, C. P.; Xavier-Filho, J.; Campos, F. A. P. Biochemical basis of the toxicity of manipueira (liquid extract of cassava roots) to nematodes and insects. Phytochemical Analysis, v.11, p.57-60, 2000.

Malavolta, E. Avaliação do estado nutricional das plantas: Princípios e aplicações. 2.ed. Piracicaba: Potafos, 1997.319p.

Mantovani, J. R.; Ferreira, M. E.; Cruz, M. C. P. Produção de alface e acúmulo de nitrato em função da adubação nitrogenada. Horticultura Brasileira, v.23, p.758-762, 2005.

Mélo, R. F.; Ferreira, P. A.; Ruiz, H. A.; Matos, A. T.; Oliveira, L. B. O. Alterações físicas e químicas em três solos tratados com água residuária de mandioca. Irriga, v.10, p.383-392, 2005.

Nasu, E. G. C.; Pires, E.; Fermentini, H. N.; Furlanetto, C. Efeito de manipueira sobre Meloidogyne incognita em ensaios in vitro e em tomateiros em casa de vegetação. Tropical Plants Pathology, v.35, p.32-36, 2010. 
Prado, R. M.; Braghirolli, L. F.; Natale, W.; Corrêa, M. C. M.; Almeida, E. V. de. Aplicação de potássio no estado nutricional e na produção de matéria seca de mudas de maracujazeiro-amarelo. Revista Brasileira de Fruticultura, v.26, p.295-299, 2004.

Pinho, M. M. C. A. de. Características químicas de solos adubados com manipueira. Recife: UFRPE, 2007. 56p. Dissertação Mestrado

Resende, G. M.; Alvarenga, M. A. R.; Yuri, J. E.; Souza, R. J.; Mota, J. H.; de Carvalho, J. G. Rodrigues Júnior, J. C. Rendimento e teores de macronutrientes em alface tipo americana em função de doses de nitrogênio e molibdênio em cultivo de verão. Ciência e Agrotecnologia, v.33, p.153$163,2009$.

Ribas, M. M. F.; Cereda, M.P.; Villas Boas, R.L. Use of cassava wastewater treated anaerobically with alkaline agents as fertilizer for maize (Zea mays L.). Brazilian Archives of Biology and Technology, v.53, p.55-62, 2010.

Sandri, D.; Matsura, E. E.; Testalef, R. Desenvolvimento da alface Elisa em diferentes sistemas de irrigação com água residuária. Revista Brasileira de Engenharia Agrícola e Ambiental, v.11, p.17-29, 2007.
Santos, M. H. V.; Araújo, A C. de.; Santos, D. M. R.; Lima, N. S.; Lima, A. C. A.; Lima, C. L. C.; Santiago, A. D. Uso da manipueira como fonte de potássio na cultura da alface (Lactuca sativa, L.) cultivada em casa-de-vegetação. Acta Scientiarum Agronomy, v.32, p.729-733, 2010.

Silva, F. F.; Freitas, P. S. L.; Bertonha, A.; Rezende, R.; Gonçalves, A. C. A.; Dallacort, R. Flutuação das características químicas do efluente industrial de fecularia de mandioca. Acta Scientiarum Agronomy, v.25, p.167-175, 2003.

Schwengber, J. A. M.; Silva, F. F.; Smiderle, O. J.; Schewengber, D. R. Nodulação do feijão-caupi em função da aplicação de três águas de farinheira. Revista em Agronegócios e Meio Ambiente, v.3, p.135-146, 2010.

Teixeira, N. T.; de Paula, E. L.; Fávari, D. B.; Almeida, F.; Guarnieri. V. Aduabação orgânica e organo-mineral e algas marinhas na produção de alface. Revista Ecossistemas, v.29, p.19-22, 2004.

Vieites, R. L. Efeitos da adubação com manipueira sobre o rendimento e qualidade dos frutos de tomate. Pesquisa Agropecuária Brasileira, v.33, p.45-47, 1998.

Wosiacki, G.; Cereda, M. P. Valorização de resíduos de processamento da mandioca. PublicatioUEPG, v.8, p.27-43, 2002. 